\title{
Role of inflammatory markers in predicting hepatocellular carcinoma recurrence after liver transplantation
}

\author{
Nourhan Badwei ${ }^{1 *}$ DI, Waheed A. Monsef ${ }^{1}$, Iman Montasser ${ }^{1}$, Mohamed Bahaa ${ }^{2}$, Mahmoud El Meteini ${ }^{2}$ and \\ Shimaa Y. Kamel ${ }^{1}$
}

\begin{abstract}
Background: Liver transplantation (LT) is the best treatment for selected patients with cirrhosis and small hepatocellular carcinoma (HCC) who are not candidates for resection. The proinflammatory effects of systemic inflammatory response have been linked with HCC. Therefore, the measurement of inflammatory markers represents a significant tool to limit recurrence after LT.
\end{abstract}

Results: There are eleven patients with HCC recurrence post-transplantation. Pre-transplantation AFP can predict HCC recurrence with the best cutoff value of $\geq 17.8 \mathrm{ng} / \mathrm{ml}$ with a sensitivity of $82 \%$ and specificity of $70 \%$. Posttransplantation CRP can predict HCC recurrence with the best cutoff value of $\geq 0.85(\mathrm{mg} / \mathrm{dl})$ with a sensitivity of $73 \%$ and specificity of $71 \%$. Other inflammatory markers NLR and PLR were not significant in predicting HCC recurrence. Moreover, HCC recurrence significantly affects the outcome of patients undergoing LT ( $p$ value $<0.001$ ) with a worse prognosis.

Conclusion: Our results showed additional benefits of inflammatory markers as CRP to standard parameters in predicting HCC recurrence to refine recipient selection and achieve better survival outcomes post-LT.

Keywords: Liver transplantation, HCC recurrence, Inflammatory markers, Outcome

\section{Background}

Liver transplantation is a highly effective therapy for early-stage HCC because it offers optimal treatment of both the underlying liver disease and the tumor, and also, it provides an excellent long-term survival rate [1]. The Milan criteria are widely used for patient selection for liver transplantation in patients with HCC. However, the recurrence rate of HCC is approximately $15-20 \%$ [2], even among patients who fulfill the Milan criteria. The outcome of liver transplantation in the existence of such recurrence is poor [3].

Different factors are incriminated in the development of HCC; one of them is inflammation as it promotes

\footnotetext{
* Correspondence: nourhanbadwei1990@gmail.com

'Tropical Medicine, Gastroenterology and Hepatology, Faculty of Medicine, Ain Shams University, Cairo, Egypt

Full list of author information is available at the end of the article
}

liver malignant transformation through upregulation of cytokines and mediators that inhibit apoptosis, promote angiogenesis, and damage DNA [4].

Moreover, they facilitate angiogenesis and tumor progression through activation of different oncogenes as $R A S$ and $M Y C$ resulting in cytokine-rich tumor microenvironment and granulocyte recruitment and activation [5].

During necrosis, the progression of hypoxia to anoxia in the tumor can elicit the innate immune response as a consequence of complement cascade activation and opsonin release leading to an overall rise in the neutrophil count [6]. Therefore, inflammatory indices as neutrophil to lymphocyte ratio (NLR), the platelet to lymphocyte ratio (PLR), and C-reactive protein (CRP) have been widely investigated as prognostic values for HCC [7].

\section{Springer Open}

(-) The Author(s). 2021 Open Access This article is licensed under a Creative Commons Attribution 4.0 International License, which permits use, sharing, adaptation, distribution and reproduction in any medium or format, as long as you give appropriate credit to the original author(s) and the source, provide a link to the Creative Commons licence, and indicate if changes were made. The images or other third party material in this article are included in the article's Creative Commons licence, unless indicated otherwise in a credit line to the material. If material is not included in the article's Creative Commons licence and your intended use is not permitted by statutory regulation or exceeds the permitted use, you will need to obtain permission directly from the copyright holder. To view a copy of this licence, visit http://creativecommons.org/licenses/by/4.0/. 
The NLR is a measure of the proportion of peripheral blood neutrophils to lymphocytes and has an important role in predicting outcomes in several malignancies [8].

On the other hand, the platelets exacerbate the inflammatory response by releasing proteins such as platelet-derived growth factor (PDGF) and transforming growth factors $\alpha$ and $\beta$ (TGF). As regards PLR, it is a simple laboratory test that measures the proportion of platelets to lymphocytes and can be used as a marker of inflammation [9].

Also, Xia et al. [10] found that elevated PLR Pre-LT is associated with advanced pathological data including larger tumor size, multiple tumors, and microvascular and macrovascular tumor invasion.

C-reactive protein is an acute-phase reactant that is synthesized primarily by hepatocytes [11]. There has been a growing interest in its role in predicting $\mathrm{HCC}$ outcomes post-LT [12]. It is considered a useful tool in predicting response to various treatment options and long-term survival afterwards [13].

Also, inflammatory biomarkers are incorporated into scoring systems with tumor size and number that will improve our ability to predict outcomes in HCC patients post-liver transplantation [7].

\section{Methods}

\section{Patient selection}

This study was conducted at the Ain-Shams Center for Organ Transplantation (ASCOT) unit preserving the rights and privacy of patients' data. A retrospective study included 100 participants with HCC with the following criteria:

\section{Inclusion criteria}

HCC patients aged 18-60 years fulfilled Milan/Modified San Fransisco Criteria, underwent living donor liver transplantation LDLT during the study period from March 2008 till March 2018.

\section{Exclusion criteria}

Exclusion criteria are pre- or post-transplant sepsis, active or recent history of massive gastrointestinal hemorrhage at the time of LT, and history of hematopoietic agents within the month before LT.

\section{Statistical analysis}

A two-sided binomial test was used to show the role of inflammatory markers as prognostic values for determining HCC recurrence post-LT; the data was collected, revised, coded, and entered into the statistical package for social science SPSS version 20; and the data was presented as the number and percentage. Receiver operating characteristic (ROC) curves were generated, and the area under the curve (AUC) was calculated to evaluate the discriminatory ability of inflammatory markers and AFP providing cutoff values to stratify the patient population.

\section{Diagnosis of the studied cases}

Data were retrieved from the file system of the included patients. HCC was diagnosed according to EASL guidelines (2018), and we have focused on 1-week pretransplantation to document the laboratory investigations including $\mathrm{CBC}$ with differential (commenting on absolute neutrophil, lymphocyte, and platelet count to calculate platelet/lymphocyte, neutrophil/lymphocyte ratios), CRP and AFP, Pre-operative Child-Turcotte-Pugh Scoring System, and postoperative laboratory investigations (NLR, PLR, AFP, CRP) after 1 week, in addition to the histological examination of the explant pathology to assess the microvascular invasion and the grade of differentiation according to Edmondson and Steiner Grading System. Grade I consists of small tumor cells, arranged in trabeculae with abundant cytoplasm and minimal nuclear irregularity indistinguishable from normal liver tissue, Grade II tumors have prominent nucleoli, hyperchromatism, and moderate nuclear irregularity, Grade III shows more pleomorphism than grade II and have angulated nuclei, and Grade IV has prominent pleomorphism with often anaplastic giant cells.

\section{Transplantation and follow-up}

All LT was performed using the living donor liver transplantation technique. As regards postoperative immunosuppression, our regular protocol includes corticosteroids in the form of methylprednisolone and tapered gradually to be stopped within 3 months.

Besides that, calcineurin inhibitors (CNIs) and antimetabolites (MMF) are added, and MMF is usually stopped at 1-year post-transplantation. Regarding the HCC recipient protocol, we adopted customized immunosuppressive therapy in the form of steroids tapered over 3 months and CNI monotherapy to note that the trough level is kept on a lower level that maintains stable liver functions without rejection.

At our transplantation unit, patients were followed-up by AFP and liver ultrasonography once weekly during the 1 st 6 weeks post-LT and then every 2 weeks for the next 3 months, and monthly for the next 6 months at $\mathrm{OPC}$, then every 3 months for the rest of the 1st year, and after that, every 3-6 months according to the scheduled follow-up visit. CT and/or PET scan is done whenever needed according to the results of U $\backslash S$ and AFP.

\section{Results}

The demographic features of the studied 100 participants showed that there were 91 males (\%) and 9 females $(\%)$ with their mean age $(52.26 \pm 6.27)$ years, and 
the majority of them (98\%) were HCV-positive and most of them had MELD score between 9 and 19 (72\%).

Concerning the pre-transplant child score, $23 \%$ of our patients were child $\mathrm{A}, 32 \%$ were child $\mathrm{B}$, and the rest were child C, while in Milan criteria, $78 \%$ of patients fulfilled it in our study.

As regards the explant pathology of the studied cases, post-transplantation revealed HCC grade I was found in $52(52 \%)$ of them while the rest showed HCC grade II, besides microvascular invasion in 7 (7\%) of them.

Regarding the mean Alpha-fetoprotein (AFP) (ng/ml) among our studied group, pre-LT was 107.01 \pm 47.91 and post-LT was $9.15 \pm 6.94$.

Also, their pre-transplantation inflammatory markers showed that the mean calculated PLR was (86.11 \pm 51.16), the mean NLR was $(2.43 \pm 1.39)$, and the mean $\mathrm{CRP}(\mathrm{mg} / \mathrm{dl})$ was $(4.40 \pm 2.03)$.

While post-transplantation after 1 week, the mean calculated PLR of the studied patients was (114.61 \pm 63.73$)$, the mean NLR was $(2.21 \pm 0.64)$, and the mean CRP $(\mathrm{mg} / \mathrm{dl})$ was $(0.8 \pm 0.61)$.

During the 10 years of the follow-up study period of our studied cases, after 6 months, four patients developed HCC recurrence-one of them developed a single lesion with grade III differentiation, while the other three developed multiple lesions with grade II differentiation-all of them had a microvascular invasion.
After 1 year, two other patients developed HCC recurrence with multiple focal lesions with grade III differentiation with microvascular invasion. After 5 years, another five patients developed HCC recurrence with 3 of them in the form of multiple hepatic tumors. As regards the histopathological evaluation, 3 of those cases were grade III and microvascular invasion in all of them.

At the end of the study period, 11 (11\%) out of 100 cases developed HCC recurrence post-LT. Kaplan-Meier survival analysis for the time to recurrence was done and showed that the mean time to recurrence of the studied patients after liver transplantation was 2 years with $95 \%$ confidence interval (1-3) years as shown in Fig. 1.

As regards the relation between the demographic data with HCC recurrence, our results showed that there was significant relation regarding the age (years) of the cases with a mean $(47.27 \pm 4.92)$ and recurrence while no significant relation with the gender (Table 1).

Concerning the HCC recurrence and pretransplantation data as MELD, child score of the transplanted patient, and the calculated NLR, PLR, AFP, and CRP, we concluded that only AFP (ng/dl) with median $(66 \pm 50)$ showed a significant relation with HCC recurrence as shown in Table 2.

The recurrence of $\mathrm{HCC}$ and post-transplantation data of the studied patients showed that there was a significant relation regarding CRP $(\mathrm{mg} / \mathrm{dl})$ with median $(1.50 \pm$

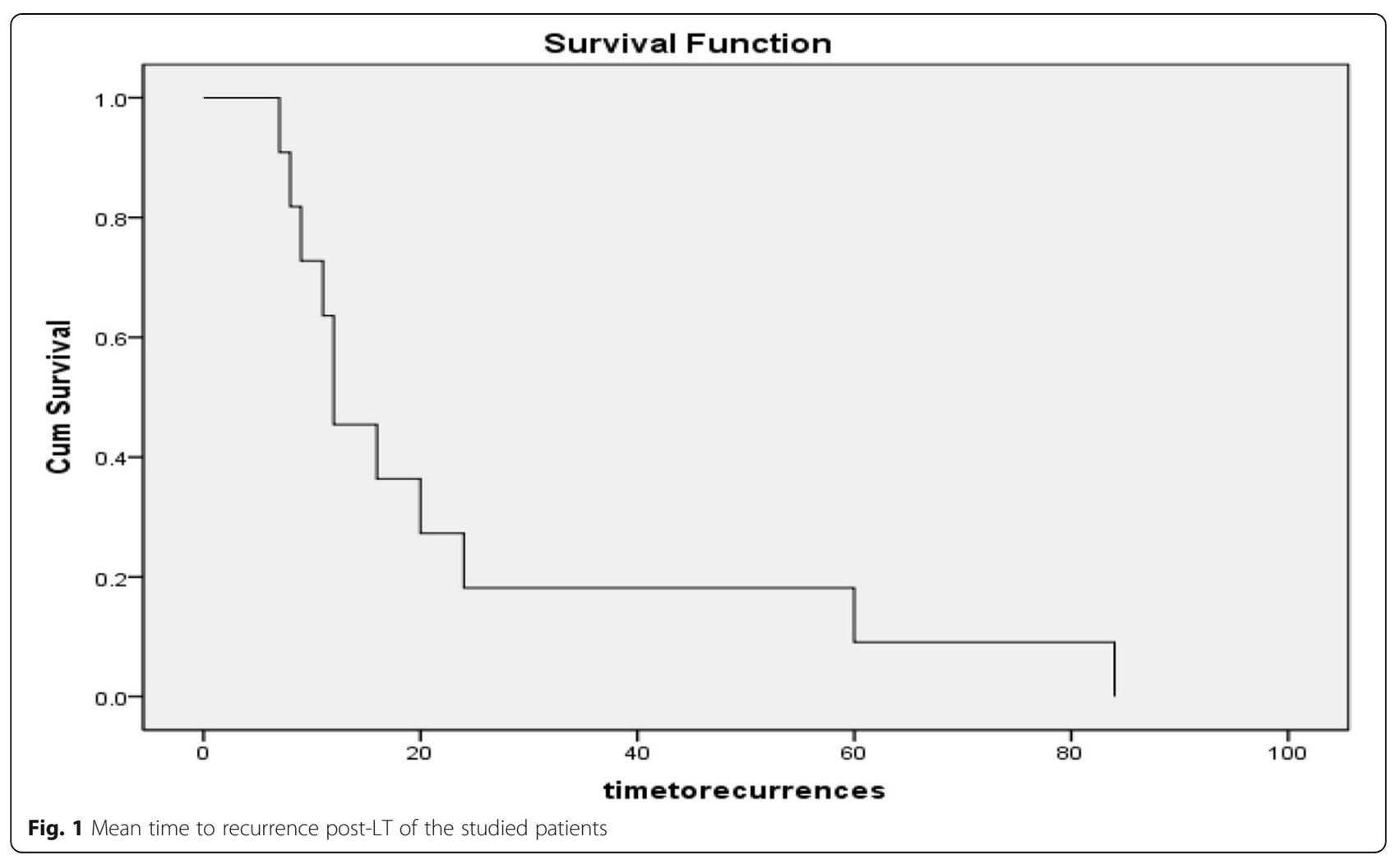


Table 1 The relation between the demographic data and HCC recurrence

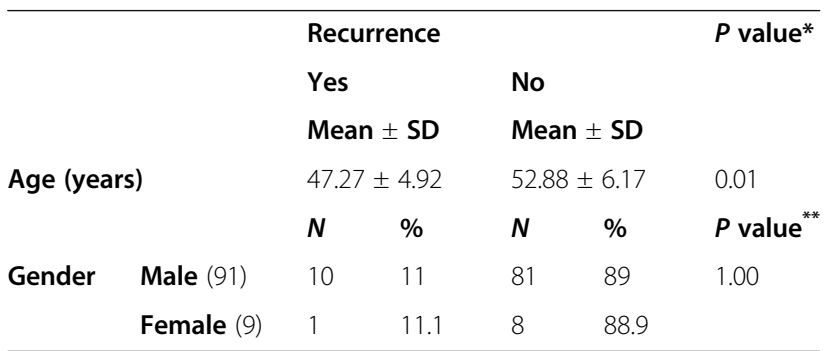

"Student $t$ test

${ }^{* *}$ Chi-squared test

1.30) and those who had microvascular invasion in the explant pathology (Table 3).

Regarding the ROC curve of predictive ability of pretransplantation AFP, CRP, PLR, and NLR for the prediction of HCC recurrence as illustrated in Fig. 2 showed that only pre-transplantation AFP can predict HCC recurrence with best cutoff value $\geq 17.8 \mathrm{ng} / \mathrm{ml}$ with a sensitivity of $82 \%$ and specificity of $70 \%$ as AUC 0.776 with 95\%CI (0.654-0.897) ( $p$ value $=0.003$ )

Post-transplantation showed that only CRP can predict $\mathrm{HCC}$ recurrence with best cutoff value $\geq 0.85 \mathrm{mg} / \mathrm{dl}$ with a sensitivity $73 \%$ and specificity of $71 \%$ as AUC 0.807 with $95 \%$ CI $(0.672-0.943)$ ( $p$ value $=0.001)$ as described in Fig. 3.

During the10 years of follow-up, 16 out of the total 100 studied cases died, 9 (56\%) of them died with HCC recurrence while other causes of mortality were listed in Table 4.

So it was found out that $\mathrm{HCC}$ recurrence significantly affects the outcome of patients undergoing LT $(p<0.001)$ (Tables 4 and 5).

Finally, regarding the cumulative overall survival of the studied patients, $100(100 \%)$ according to the presence or absence of HCC recurrence after liver transplantation showed that the mean time to death (survival time) of those without HCC recurrence 89 (89\%) was 9 years with $95 \%$ confidence interval of $8-$ 10 years, while the others with HCC recurrence 11 (11\%) was 2.5 years with $95 \%$ confidence interval of $1-4$ years as described in Fig. 4.

\section{Discussion}

Hepatocellular carcinoma (HCC) represents about 90\% of primary liver cancers, and also, it is the 5th most common cancer in the world and the 3rd cause of cancer-related mortality as estimated by the World Health Organization [14].

As regards surgical treatment for $\mathrm{HCC}$, initially it started with resection but soon grew to include liver transplantation (LT) which is potentially curative and has become increasingly more common and successful [7].

Although the Milan criteria lower the risk of $\mathrm{HCC}$ recurrence and improve the survival of those patients, still 15-20\% experience recurrence after transplantation. So

Table 2 The relation between pre-transplantation data and HCC recurrence

\begin{tabular}{|c|c|c|c|c|c|c|}
\hline & & \multicolumn{4}{|l|}{ Recurrence } & \multirow[t]{3}{*}{$P$ value* } \\
\hline & & Yes & & No & & \\
\hline & & \multicolumn{2}{|l|}{ Mean \pm SD } & \multicolumn{2}{|l|}{ Mean $\pm S D$} & \\
\hline PLR & & \multicolumn{2}{|l|}{$100.27 \pm 46.17$} & \multicolumn{2}{|l|}{$\begin{array}{l}84.36 \pm \\
51.72\end{array}$} & 0.33 \\
\hline NLR & & \multicolumn{2}{|l|}{$2.06 \pm 0.37$} & \multicolumn{2}{|l|}{$2.47 \pm 1.46$} & 0.03 \\
\hline AFP (ng/ml) & & \multicolumn{2}{|l|}{$66 \pm 50$} & \multicolumn{2}{|l|}{$17.10 \pm 7.60$} & $0.003^{\#}$ \\
\hline \multirow{2}{*}{\multicolumn{2}{|c|}{ CRP (mg/ml) }} & \multicolumn{2}{|l|}{$2.50 \pm 1$} & \multicolumn{2}{|l|}{$1.10 \pm 0.70$} & $0.43^{\#}$ \\
\hline & & Recurrence & $\%$ & Non-recurrence & $\%$ & $P$ value $^{* *}$ \\
\hline \multirow[t]{3}{*}{ MELD score } & 1) Up to 9 (17) & 2 & 11.8 & 15 & 88.2 & \multirow[t]{3}{*}{0.54} \\
\hline & 2) Above 9 and up to $19(72)$ & 9 & 12.5 & 63 & 87.5 & \\
\hline & 3) Above 19 (11) & 0 & 0.0 & 11 & 100 & \\
\hline CTP A score & Up to $6(23)$ & 4 & 17.4 & 19 & 82.6 & 0.26 \\
\hline \multirow[t]{2}{*}{ CTP B score } & Early (up to 7) (8) & 3 & 37.5 & 5 & 62.5 & \multirow[t]{2}{*}{0.84} \\
\hline & Late (up to 9) (24) & 2 & 8.3 & 22 & 91.7 & \\
\hline CTP C score & Up to $15(45)$ & 2 & 4.4 & 43 & 95.6 & 0.06 \\
\hline
\end{tabular}

"Student $t$ test

${ }^{* *}$ Chi-squared test (FE Fisher's exact test)

"Median and IQR (Mann-Whitney $U$ test) 
Table 3 The relation between post-transplantation data and HCC recurrence

\begin{tabular}{|c|c|c|c|c|c|c|}
\hline & & \multicolumn{4}{|c|}{ Recurrence } & \multirow[t]{3}{*}{$P$ value* } \\
\hline & & \multicolumn{2}{|c|}{ Yes } & \multicolumn{2}{|l|}{ No } & \\
\hline & & \multicolumn{2}{|c|}{ Mean \pm SD } & \multicolumn{2}{|c|}{ Mean \pm SD } & \\
\hline PLR & & \multicolumn{2}{|c|}{$97.09 \pm 49.06$} & \multicolumn{2}{|c|}{$116.7 \pm 65.21$} & 0.34 \\
\hline NLR & & \multicolumn{2}{|c|}{$2.16 \pm 0.59$} & \multicolumn{2}{|c|}{$2.2 \pm 0.65$} & 0.80 \\
\hline CRP $(\mathrm{mg} / \mathrm{ml})$ & & \multicolumn{2}{|c|}{$1.50 \pm 1.30$} & \multicolumn{2}{|c|}{$0.60 \pm 0.40$} & $0.001^{\#}$ \\
\hline \multirow[t]{2}{*}{ AFP $(\mathrm{ng} / \mathrm{ml})$} & & \multicolumn{2}{|c|}{$28.00 \pm 10.00$} & \multicolumn{2}{|c|}{$4.00 \pm 2.40$} & $0.09^{\#}$ \\
\hline & & $N$ & $\%$ & $N$ & $\%$ & $P$ value ${ }^{* *}$ \\
\hline \multirow[t]{2}{*}{ Grade of HCC } & Grade I & 3 & 5.8 & 49 & 94.2 & \multirow[t]{2}{*}{0.08} \\
\hline & Grade II & 8 & 16.7 & 40 & 83.3 & \\
\hline \multirow[t]{2}{*}{ Microvascular invasion } & No & 5 & 5.4 & 88 & 94.6 & \multirow[t]{2}{*}{$<0.001$} \\
\hline & Yes & 6 & 85.7 & 1 & 14.3 & \\
\hline
\end{tabular}

"Student $t$ test

${ }^{* *}$ Chi-squared test (FE Fisher's exact test)

\#Median and IQR (Mann-Whitney $U$ test)

the outcome of liver transplantation depends on the recurrence of HCC as well as its progression post-LT [15].

The histopathological examination of the explant pathology to assess the microvascular invasion and the grade of differentiation was used to predict $\mathrm{HCC}$ recurrence as tumor biology is an important risk factor for recurrence [1].

So assessing tumor biology for the risk of recurrence noninvasively by biomarkers is essential. The measurement of inflammatory markers represents a significant

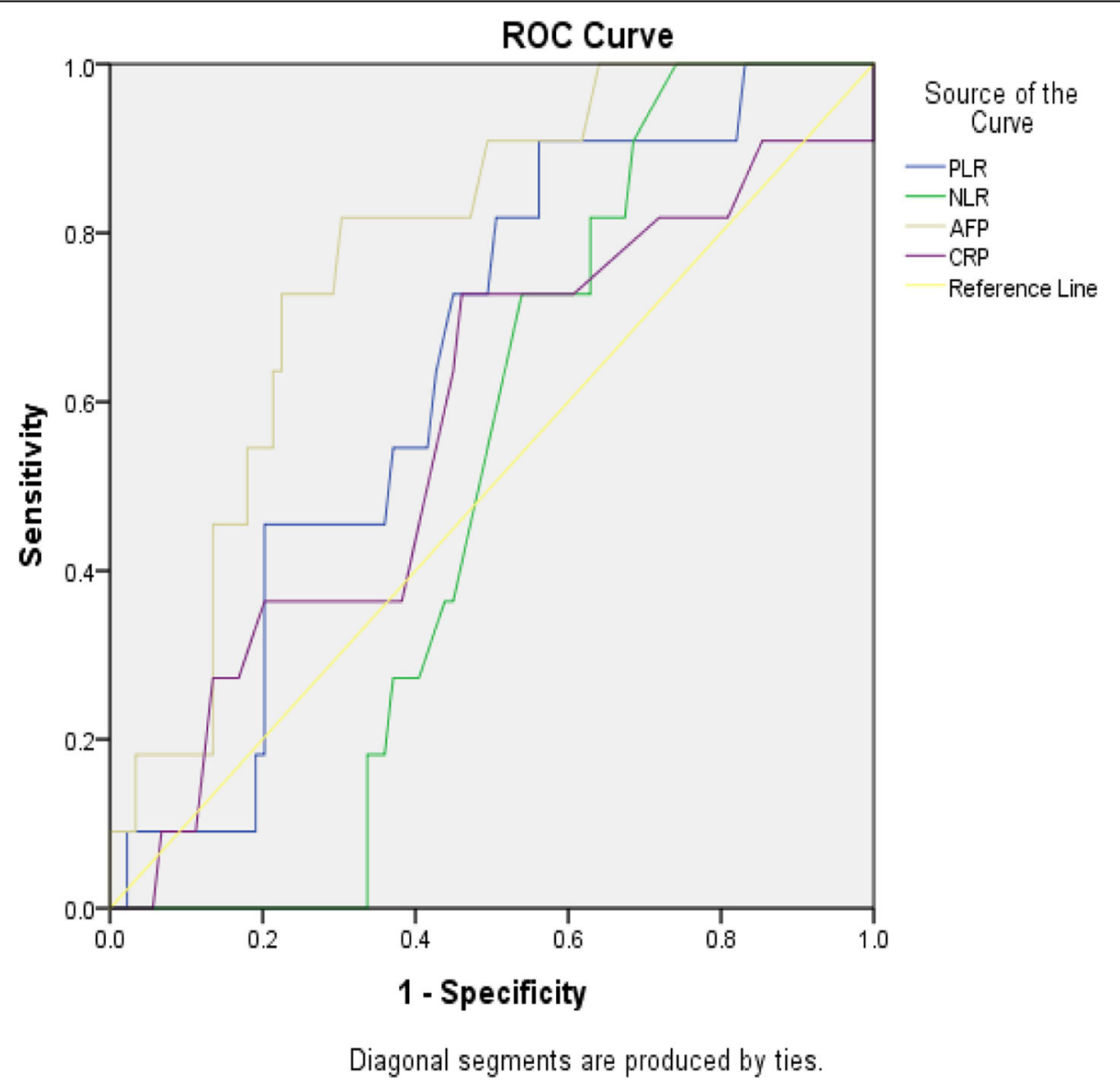

Fig. 2 Predictive ability of pre-transplantation AFP, CRP, PLR, and NLR for prediction of HCC recurrence 


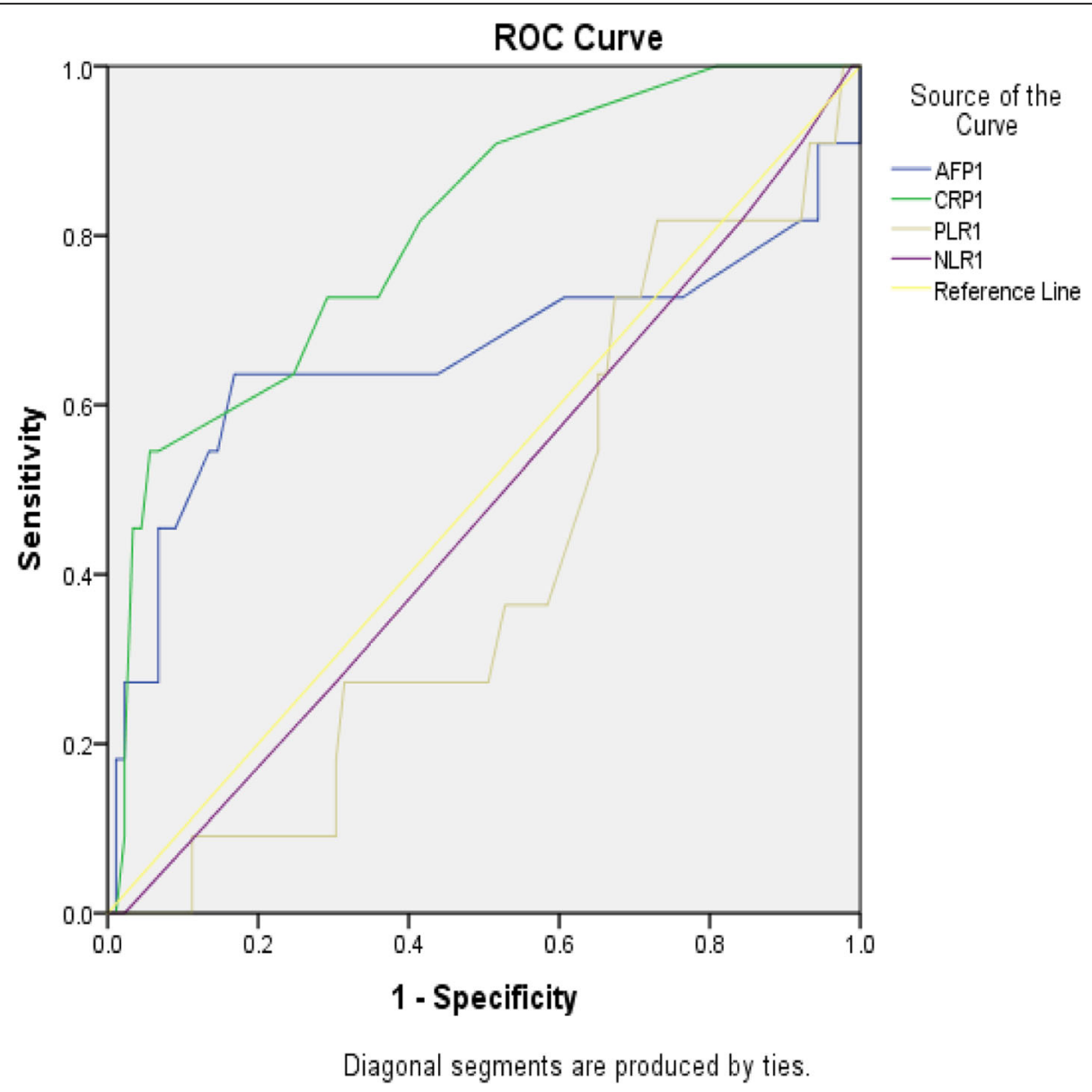

Fig. 3 Predictive ability of post-transplantation AFP, CRP, PLR, and NLR for prediction of HCC recurrence

tool to assess the risk of HCC recurrence post-LT as the proinflammatory effects of a systemic inflammatory response (SIR) have been linked with HCC [16].

Among the inflammatory indices, the NLR, the PLR, and CRP have been widely investigated as prognostic values for determining post-therapeutic $\mathrm{HCC}$ recurrence and survival [7].
In our study, regarding the etiology of the studied cases, 98 (98\%) are HCV-positive. In fact, there are controversial reports on the influence of hepatitis $\mathrm{C}$ on the risk of $\mathrm{HCC}$ recurrence after LT.

However, Vasavada and Chan [17] reported an association of viral infection with lower 5-year recurrence-free survival (RFS) in the subgroup of hepatitis $C$ patients as

Table 4 Outcome after 10 years of follow-up

\begin{tabular}{llll}
\hline & & No of patients & $\%$ \\
\hline Outcome & Alive & 84 & 84 \\
Cause of death $(N=16)$ & Dead & 16 & 16 \\
& HCC recurrence & 9 & 56.3 \\
& Graft rejection & 2 & 12.5 \\
& Other tumors (lymphoma/sarcoma) & 2 & 12.5 \\
& C.N.S sequaele (stroke) & 1 & 6.3 \\
& Biliary complications & 1 & 6.3 \\
& Car accident & 1 & 6.3 \\
\hline
\end{tabular}


Table 5 Percentage of dead patients with HCC recurrence from all dead patients

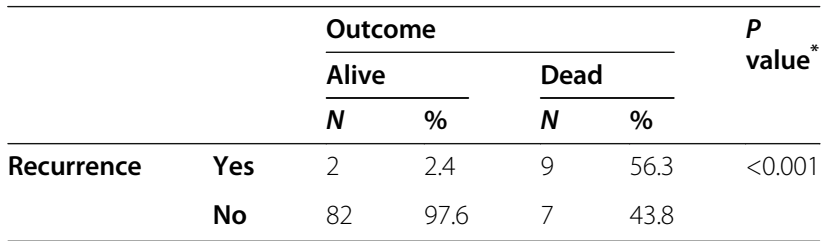

*Student $\mathrm{t}$ test

a result of rapid development of liver fibrosis after living-donor LT.

In the present study, the explant pathology of our studied cases post-LT revealed that microvascular invasion MVI was found in 7 (7\%) of them; besides, HCC grade I was found in 52 (52\%) while the rest showed HCC grade II.

These results agree with Mehta et al. [18] who conducted their study on 911 HCC patients and concluded that MVI was found in the explant pathology of 10 (10\%) of patients, and also, $40 \%$ of their patients had $\mathrm{HCC}$ grade I and $45 \%$ had $\mathrm{HCC}$ grade II.

In our study, after 10 years of the follow-up period, we found out that the total number of patients with $\mathrm{HCC}$ recurrence was 11 (11\%) out of 100 cases. In concordance with our results, Nissen et al. [19] who reported that 13 (11\%) out of 122 HCC patients developed HCC recurrence post-LT during the 8 years of follow-up.

Therefore, it is necessary to identify different risk factors for tumor recurrence TR to refine the patient selection. Also, it is important to define recipients who need closer follow-up and to identify modifiable factors that may reduce the incidence of TR [20].

Concerning the correlation between different parameters and HCC recurrence, firstly the demographic data of the studied patients showed that there was significant relation regarding the age of the cases with mean (47.27 \pm 4.92 ) years and $\mathrm{HCC}$ recurrence $(P$ value $=0.01)$.

This is against the results reported by Chan et al. [21] who conducted their study on 126 patients and concluded that that age was not a significant predictor for $\mathrm{HCC}$ recurrence post-LT.

This may be attributed to that usually HCC patients aged $>60-70$ years are not considered as potential candidates for LT because of the increased comorbidity in elderly patients, so most of the studied candidates are younger than that age as our study [21].

Regarding pre-transplantation data of the studied cases showed that there was a significant relation regarding AFP (ng/dl) with median $(66 \pm 50)$ and HCC recurrence $(P$ value $>0.01)$ while no significant relation with NLR, PLR, and CRP.

This partially agrees with Citores et al. [22] who summarized 9 studies and found that elevated pre-LT AFP level is an independent risk factor for HCC recurrence in 8 out of 9 studies.

Regarding the systemic inflammatory markers, they reported that NLR was found to be associated with HCC recurrence in 6 out of 9 studies and CRP in 1 out of 2 studies, while PLR was not shown as an independent risk factor in any of the 4 studies in which it was analyzed [22].

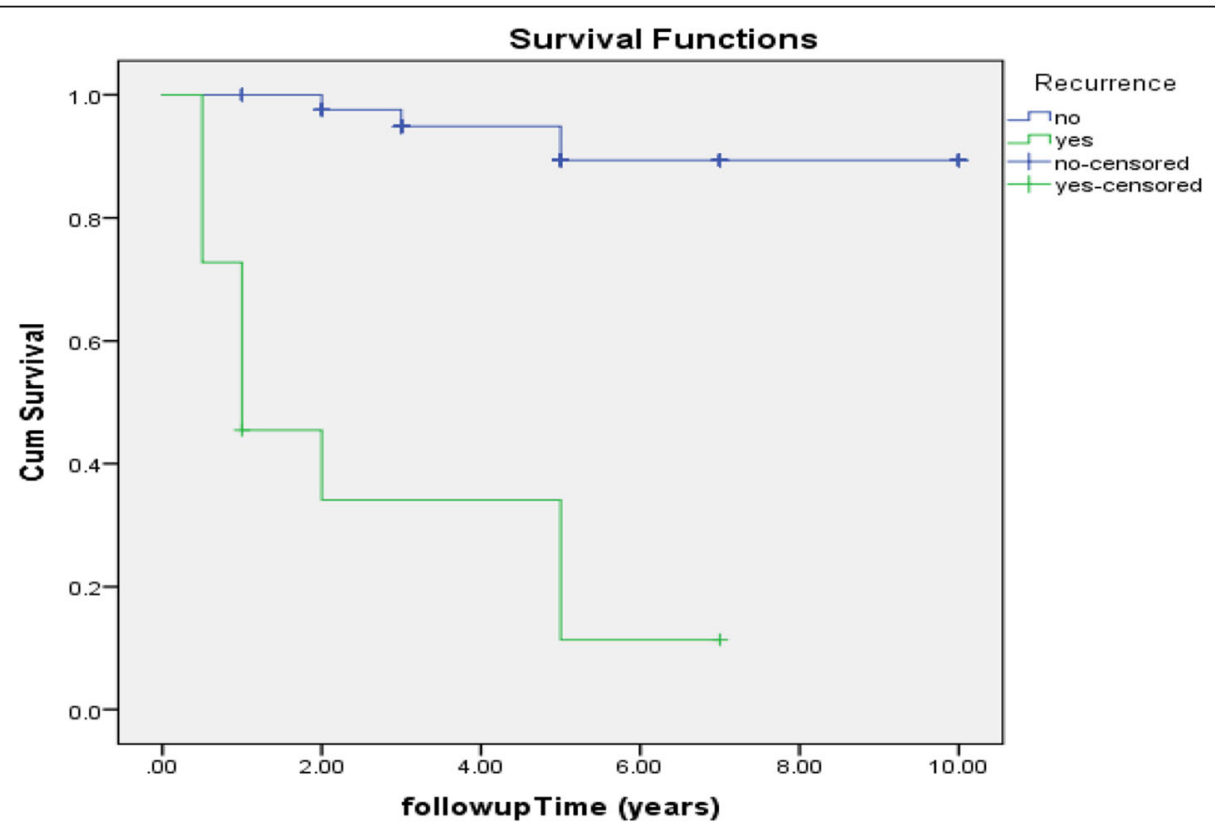

Fig. 4 The cumulative overall survival of patients according to the presence or absence of HCC recurrence 
So, the authors concluded that the utility of systemic inflammatory markers as prognostic markers for patient selection for LT is limited and they cannot be universally applied in all patients, and most of the data are based on very few retrospective studies, with most having small sample sizes [22].

On the contrary, Halazun et al. [23] were the first to demonstrate the link between NLR and liver malignancies in patients who underwent surgery for colorectal liver metastasis. After that, many studies identified NLR as an independent risk factor for HCC recurrence, along with microvascular invasion and/or tumor size and number in some studies, but not in others $[24,25]$ which disagree with our results.

Also, the prognostic significance of PLR for HCC recurrence after LT has been less extensively studied than that of NLR, but in a recent systematic review and metaanalysis including 899 patients from five studies, high PLR was associated with a significant increase of HCC recurrence after LT [26].

Moreover, Pinato et al. [27], Lai et al. [28], and Xia et al. [10] evaluated PLR as a post-therapeutic HCC prognostic marker.

In addition, a meta-analysis of 24 studies by Zheng et al. [29] comprising 6318 patients with HCC, confirmed that the NLR and PLR can be used as prognostic markers for predicting post-therapeutic $\mathrm{HCC}$ recurrence.

As regards post-transplantation data of our studied patients, it showed that there was a significant relation regarding those who had microvascular invasion in the explant pathology and HCC recurrence $(P$ value $>0.01)$. The previous data goes with Chan et al. [21] who studied 17 out of 126 patients with HCC recurrence following LT and concluded that the presence of microvascular invasion was an independent prognostic factor for HCC recurrence.

Therefore, pre-LT elevated alpha-fetoprotein (AFP) and the presence of microvascular invasion (MVI) have been identified as the most commonly independent predictors of overall survival OS and recurrence-free survival RFS in HCC patients post-LT [25] that goes with our results.

Moreover, in our study, the ROC curve of the predictive ability of AFP for detection of HCC recurrence postLT showed that it can predict $\mathrm{HCC}$ recurrence with the best cutoff value of $>17.8 \mathrm{ng} / \mathrm{ml}$ with a sensitivity of $82 \%$ and specificity of $70 \%$.

Interestingly, the 9 studies analyzing pre-LT AFP level, except for one [30], found AFP to be an independent risk factor for HCC recurrence [22] which supports our results.

Our results also were near to Berry and Ioannou [31] who reported that HCC recipients with serum AFP level $>15 \mathrm{ng} / \mathrm{ml}$ at transplant time had worse post-transplant mortality and shorter recurrence-free survival.
Also, Lai et al. [26] found that AFP > $200 \mathrm{ng} / \mathrm{mL}$ was the best prognostic factor with an area under the receiver operating characteristic curve (AUC) of 70.6.

Regarding the ROC curve of predictive ability of posttransplantation CRP in our study showed that it can predict HCC recurrence with the best cutoff value of $\geq 0.85$ $(\mathrm{mg} / \mathrm{dl})$ with a sensitivity of $73 \%$ and specificity of $71 \%$.

This agrees with Kornberg et al. [32] who concluded that elevated CRP level $>3.5 \mathrm{mg} / \mathrm{dl}$ in post-transplant patients with $\mathrm{HCC}$ was an independent predictor of poor recurrence-free survival.

Also, several studies have reported that the elevated CRP level independently predicts poor outcomes in HCC patients undergoing living donor LT [33].

Moreover, it was found out that that elevated serum CRP was associated with more aggressive tumor behavior and spread pre- and post-LT [34]. Moreover, Na et al. [35], Mori et al. [36], and Kim et al. [37] reported the usefulness of using preoperative CRP for prognosis of HCC recurrence post-LT.

Regarding the relation between $\mathrm{HCC}$ recurrence and outcome post-LT in our study, it showed that HCC recurrence significantly affects the outcome of patients undergoing LT $(p<0.001)$.

This is in concordance with Chan et al. [21] who found that the prognosis of 17 (13.5\%) out of 126 patients with HCC recurrence following LT patients was very poor $(p<0.001)$.

Finally, regarding the survival analysis according to the presence or absence of HCC recurrence in our study, it is concluded that the mean time to death (survival time) of the studied patients without HCC recurrence 89 (89\%) after liver transplantation was 9 years with $95 \%$ confidence interval 8-10 years, while those with HCC recurrence 11 (11\%) was 2.5 years with $95 \%$ confidence interval $1-4$ years.

The previous data are near to Meischl et al. [38] who reported the median overall survival OS of the total study population post-LT was 11 years, while those with HCC recurrence had a significantly shorter survival with a median overall survival OS of 3.5 years with $95 \%$ CI.

Moreover, they concluded that the mean time to HCC recurrence post-LT was 2 years [38], which agrees with our results and the study conducted by Clavien et al. [39] who reported that HCC recurrence usually occurs in $8-20 \%$ of recipients and is usually seen during the first 2 years after LT.

The limitation of the current study is that it was a retrospective trial with a limited sample size, although the pro-inflammatory markers did not significantly affect the HCC recurrence, yet more retrospective studies with a larger number of patients are needed to reach the final decision on their role in the HCC recurrence. 


\section{Conclusion}

The rate of $\mathrm{HCC}$ recurrence post-liver transplantation during the 10 years of follow-up was 11 (11\%) out of 100 cases.

Pre-transplant AFP can predict HCC recurrence with the best cutoff value of $\geq 17.8 \mathrm{ng} / \mathrm{ml}$ with a sensitivity of $82 \%$ and specificity of $70 \%$.

Post-transplant CRP can predict $\mathrm{HCC}$ recurrence with the best cutoff value of $\geq 0.85(\mathrm{mg} / \mathrm{dl})$ with a sensitivity of $73 \%$ and specificity of $71 \%$.

The mean time to HCC recurrence after liver transplantation was 2 years with a $95 \%$ confidence interval.

The mean time to death (survival time) of HCC patients without recurrence after liver transplantation was 9 years with a 95\% confidence interval while those with recurrence was 2.5 years with a $95 \%$ confidence interval.

$\mathrm{HCC}$ recurrence significantly affects the outcome of patients undergoing LT $(p<0.001)$. Therefore, the prognosis of patients with $\mathrm{HCC}$ recurrence following LT remained very poor.

\section{Abbreviations}

HCC: Hepatocellular carcinoma; NLR: Neutrophil to lymphocyte ratio; PLR: Platelet to lymphocyte ratio; LT: Liver transplantation; LDLT: Living donor liver transplantation; AFP: Alpha-fetoprotein; CRP: C-reactive protein; PDGF: Platelet-derived growth factor; TGF: Transforming growth factor; ASCOT: Ain-Shams Center for Organ Transplantation; ROC: Receiver operating characteristic; AUC: Area under the curve; CNIs: Calcineurin inhibitors; SIR: Systemic inflammatory response; MVI: Microvascular invasion; TR: Tumor recurrence; OS: Overall survival

\section{Acknowledgements}

Not applicable.

\section{Authors' contributions}

N. B. collected the patients' data. I. M., S. Y. K., and N. B. contributed to the design and implementation of the research, to the analysis of the results, and to the writing of the manuscript. W. A. M., M. B., and M. EM. contributed also to the design and critical final revision with editing. The authors have read and approved the manuscript and ensure that this is the case.

\section{Funding}

None to declare.

\section{Availability of data and materials}

All data generated or analyzed during this study are included in this published article, and if any data is needed, it will be available from the corresponding author on reasonable request.

\section{Declarations}

\section{Ethics approval and consent to participate}

It is a retrospective study that has been reviewed and approved by the Research Ethics Committee REC, at the Faculty of Medicine, Ain Shams University FMASU REC, FWA 000017585 . Data were retrieved from the file system of the studied patients preserving the rights and privacy of patients' data.

\section{Consent for publication}

Written informed consent for publication regarding the data of the studied patients was obtained from the ASCOT unit.

\section{Competing interests}

The authors declare that they have no competing interests.

\section{Author details}

${ }^{1}$ Tropical Medicine, Gastroenterology and Hepatology, Faculty of Medicine, Ain Shams University, Cairo, Egypt. ${ }^{2}$ Hepatobiliary Surgery, Faculty of Medicine, Ain Shams University, Cairo, Egypt.

Received: 29 January 2021 Accepted: 3 May 2021

Published online: 21 May 2021

\section{References}

1. Mazzaferro V, Battiston C, Sposito C (2018) Pro (with caution): extended oncologic indications in liver transplantation. Liver Transpl. 24(1):98-103. https://doi.org/10.1002/lt.24963

2. Heimbach JK, Kulik LM, Finn RS, Sirlin CB, Abecassis MM, Roberts LR, Zhu AX, Murad MH, Marrero JA (2018) AASLD guidelines for the treatment of hepatocellular carcinoma. Hepatology. 67(1):358-380. https://doi.org/10.1 002/hep.29086

3. Jonas S, Bechstein WO, Steinmuller T et al (2001) Vascular invasion and histopathologic grading determine outcome after liver transplantation for hepatocellular carcinoma in cirrhosis. Hepatology. 33(5):1080-1086. https:// doi.org/10.1053/jhep.2001.23561

4. Balkwill F, Mantovani A (2001) Inflammation and cancer: back to Virchow? Lancet 357:539-545

5. Bihari C, Rastogi A, Shasthry SM, Bajpai M, Bhadoria AS, Rajesh S, Mukund A, Kumar A, Sarin SK (2016) Platelets contribute to growth and metastasis in hepatocellular carcinoma. APMIS. 124(9):776-786. https://doi.org/10.1111/a pm.12574

6. Li L, Xu L, Yan J et al (2015) CXCR32-CXCL1 axis is correlated with neutrophil infiltration and predicts a poor prognosis in hepatocellular carcinoma. J Exp Clin Cancer Res 34(1):129

7. Rosenblatt RE, Tafesh ZH, Halazun KJ (2017) Role of inflammatory markers as hepatocellular cancer selection tool in the setting of liver transplantation. Transl Gastroenterol Hepatol 2:95

8. Templeton AJ, McNamara MG, Šeruga B et al (2014) Prognostic role of neutrophil-to-lymphocyte ratio in solid tumors: a systematic review and meta-analysis. J Natl Cancer Inst. 106(6):dju124. https://doi.org/10.1093/jnci/ dju124

9. Coussens LM, Werb Z (2002) Inflammation and cancer. Nature. 420(6917): 860-867. https://doi.org/10.1038/nature01322

10. Xia W, Ke Q, Wang Y et al (2015) Predictive value of pre-transplant platelet to Lymphocyte ratio for hepatocellular carcinoma recurrence after liver transplantation. World J Surg Oncol 13:60

11. Dufour JF (2013) C-reactive protein, a prognostic marker in hepatocellular carcinoma. Hepatology. 57(6):2103-2105. https://doi.org/10.1002/hep.26250

12. Zheng Z, Zhou L, Gao S et al (2013) Prognostic role of C-reactive protein in hepatocellular carcinoma: a systematic review and meta-analysis. Int J Med Sci 10:653-664

13. Kinoshita A, Onoda H, Imai N, Iwaku A, Oishi M, Tanaka K, Fushiya N, Koike K, Nishino H, Matsushima M (2015) The C-reactive protein/albumin ratio, a novel inflammation-based prognostic score, predicts outcomes in patients with hepatocellular carcinoma. Ann Surg Oncol. 22:803-810

14. Ferlay J, Soerjomataram I, Dikshit R, Eser S, Mathers C, Rebelo M, Parkin DM, Forman D, Bray F (2015) Cancer incidence and mortality: sources, methods and major patters in GLOBOCAN 2012. Int J Cancer. 136(5):E359-E386. https://doi.org/10.1002/ijc.29210

15. EASL Clinical Practice Guidelines (2016) Liver transplantation. J Hepatol. 64(2):433-485

16. Pommergaard HC, Rostved AA, Adam R et al (2018) Vascular invasion and survival after liver transplantation for hepatocellular carcinoma: a study from the European liver transplant registry. HPB (Oxford) 20(8): 768-775

17. Vasavada BB, Chan CL (2015) Rapid fibrosis and significant histologic recurrence of hepatitis $C$ after liver transplant is associated with higher tumor recurrence rates in hepatocellular carcinomas associated with hepatitis C virus-related liver disease: a single center retrospective analysis. Exp Clin Transplant. 13(1):46-50

18. Mehta N, Heimbach J, Lee D, Dodge JL, Harnois D, Burns J, Sanchez W, Roberts JP, Yao FY (2017) Wait time of less than 6 and greater than 18 months predicts hepatocellular carcinoma recurrence after liver transplantation: proposing a wait time "sweet spot". Transplantation. 101(9): 2071-2078. https://doi.org/10.1097/TP.0000000000001752 
19. Nissen NN, Menon V, Bresee C et al (2011) Recurrent hepatocellular carcinoma after liver transplant: identifying the high-risk patient. HPB (Oxford) 13(9):626-632

20. Samoylova ML, Dodge JL, Yao FY, Roberts JP (2014) Time to transplantation as a predictor of hepatocellular carcinoma recurrence after liver transplantation. Liver Transplant. 20(8):937-944. https://doi. org/10.1002/lt.23902

21. Chan KM, Chou HS, Wu TJ, Lee CF, Yu MC, Lee WC (2011) Characterization of hepatocellular carcinoma recurrence after liver transplantation: perioperative prognostic factors, patterns and outcome. Asian J Surg. 34(3): 128-134. https://doi.org/10.1016/j.asjsur.2011.08.005

22. Citores MJ, Lucena $\mathrm{J}$, de la Fuente $\mathrm{S}$ et al (2019) Serum biomarkers and risk of hepatocellular carcinoma recurrence after liver transplantation. World J Hepatol. 11(1):50-64. https://doi.org/10.4254/wjh.v11.i1.50

23. Halazun KJ, Aldoori A, Malik HZ, al-Mukhtar A, Prasad KR, Toogood GJ, Lodge JPA (2008) Elevated preoperative neutrophil to lymphocyte ratio predicts survival following hepatic resection for colorectal liver metastases. Eur J Surg Oncol. 34(1):55-60. https://doi.org/10.1016/j.ejso.2007.02.014

24. Xiao GQ, Liu C, Liu DL et al (2013) Neutrophil-lymphocyte ratio predicts the prognosis of patients with hepatocellular carcinoma after liver transplantation. World J Gastroenterol. 2013:19

25. Shindoh J, Sugawara Y, Nagata R, Kaneko J, Tamura S, Aoki T, Sakamoto Y, Hasegawa K, Tanaka T, Kokudo N (2014) Evaluation methods for pretransplant oncologic markers and their prognostic impacts in patient undergoing living donor liver transplantation for hepatocellular carcinoma. Transpl Int. 27(4):391-398. https://doi.org/10.1111/tri.12274

26. Lai Q, Melandro F, Larghi LZ et al (2018) Platelet-to-lymphocyte ratio in the setting of liver transplantation for hepatocellular cancer: a systematic review and meta-analysis. World J Gastroenterol. 24(15):1658-1665. https://doi. org/10.3748/wjg.v24.i15.1658

27. Pinato DJ, Stebbing J, Ishizuka M, Khan SA, Wasan HS, North BV, Kubota K, Sharma R (2012) A novel and validated prognostic index in hepatocellular carcinoma: the inflammation based index (IBI). J Hepatol. 57(5):1013-1020. https://doi.org/10.1016/j.jhep.2012.06.022

28. Lai Q, Castro Santa E, Rico Juri JM, Pinheiro RS, Lerut J (2014) Neutrophil and platelet-to-lymphocyte ratio as new predictors of dropout and recurrence after liver transplantation for hepatocellular cancer. Transpl Int. 27(1):32-41. https://doi.org/10.1111/tri.12191

29. Zheng J, Cai J, Li H, Zeng K, He L, Fu H, Zhang J, Chen L, Yao J, Zhang Y, Yang $Y$ (2017) Neutrophil to lymphocyte ratio and platelet to lymphocyte ratio as prognostic predictors for hepatocellular carcinoma patients with various treatments: a meta-analysis and systematic review. Cell Physiol Biochem. 44(3):967-981. https://doi.org/10.1159/000485396

30. Yoshizumi T, Ikegami T, Yoshiya S, Motomura T, Mano Y, Muto J, Ikeda T, Soejima Y, Shirabe K, Maehara Y (2013) Impact of tumor size, number of tumors and neutrophil-to-lymphocyte ratio in liver transplantation for recurrent hepatocellular carcinoma. Hepatol Res. 43(7):709-716. https://doi. org/10.1111/hepr.12016

31. Berry K, loannou GN (2013) Serum alpha-fetoprotein level independently predicts post transplant survival in patients with hepatocellular carcinoma. Liver transpl. 19(6):634-645. https://doi.org/10.1002/lt.23652

32. Kornberg A, Witt U, Kornberg J, Müller K, Friess H, Thrum K (2016) Postoperative peak serum C-reactive protein is a predictor of outcome following liver transplantation for hepatocellular carcinoma. Biomarkers. 21(2):152-159. https://doi.org/10.3109/1354750X.2015.1118548

33. Sprinzl MF, Kirstein MM, Koch S, Seib ML, Weinmann-Menke J, Lang $H$, Düber C, Toenges G, Zöller D, Marquardt JU, Wörns MA, Galle PR, Vogel A, Pinter M, Weinmann A (2018) Improved prediction of survival by a risk factor-integrating inflammatory score in sorafenib-treated hepatocellular carcinoma. Liver Cancer. 8(5):387-402. https://doi.org/1 $0.1159 / 000492628$

34. Howell J, Pinato DJ, Ramaswami R et al (2017) Integration of the cancer related inflammatory response as a stratifying biomarker of survival in hepatocellular carcinoma treated with sorafenib. Oncotarget. 8(22):3616136170. https://doi.org/10.18632/oncotarget.15322

35. Na GH, Kim DG, Han JH, Kim EY, Lee SH, Hong TH, You YK (2014) Inflammatory markers as selection criteria of hepatocellular carcinoma in LDLT. World J Gastroenterol. 20(21):6594-6601. https://doi.org/10.3748/wjg V20.121.6594

36. Mori S, Choi Y, Park MS, Kim H, Hong G, Yi NJ, Lee KW, Suh KS (2014) Usefulness of preoperative $\mathrm{C}$-reactive protein and alpha-fetoprotein levels for prognostication of patients with hepatocellular carcinoma after living donor liver transplantation. Hepatogastroenterology. 61(136):2353-2358

37. Kim YK, Kim SH, Lee SD, Hong SK, Park SJ (2015) Pre-transplant serum levels of $\mathrm{C}$-reactive protein predict prognoses in patients undergoing liver transplantation for hepatocellular carcinoma. Transplant Proc. 47(3):686-693. https://doi.org/10.1016/j.transproceed.2014.11.048

38. Meischl T, Rasoul-Rockenschaub S, Györi G et al (2019) C-reactive protein is an independent predictor for hepatocellular carcinoma recurrence after liver transplantation. PLoS One. 14(5):e0216677. https://doi.org/10.1371/journal. pone.0216677

39. Clavien PA, Lesurtel M, Bossuyt PM, Gores GJ, Langer B, Perrier A, OLT for HCC Consensus Group (2012) Recommendations for liver transplantation for hepatocellular carcinoma: an international consensus conference report. Lancet Oncol. 13(1):e11-e22. https://doi.org/10.1016/S1470-2045(11)70175-9

\section{Publisher's Note}

Springer Nature remains neutral with regard to jurisdictional claims in published maps and institutional affiliations.

\section{Submit your manuscript to a SpringerOpen ${ }^{\circ}$ journal and benefit from:}

- Convenient online submission

- Rigorous peer review

- Open access: articles freely available online

- High visibility within the field

- Retaining the copyright to your article

Submit your next manuscript at $>$ springeropen.com 